\title{
O ATENDIMENTO EDUCACIONAL ESPECIALIZADO EM CUMARU- PE EM TEMPOS DE PANDEMIA DA COVID-19
}

\section{ARTIGO ORIGINAL}

BORBA, Jocélia Emília ${ }^{1}$

BORBA, Jocélia Emília. 0 atendimento educacional especializado em Cumaru- PE em tempos de pandemia da COVID-19. Revista Científica Multidisciplinar Núcleo do Conhecimento. Ano 05, Ed. 08, Vol. 15, pp. 66-78. Agosto de 2020. ISSN: 2448-0959, Link de acesso: https://www.nucleodoconhecimento.com.br/educacao/educacionalespecializado

\section{RESUMO}

Partindo do princípio que a Covid-19 é uma doença que surgiu na China, mas tomou uma proporção mundial e não tem cura e que ainda estão pesquisando uma vacina, este artigo tem o objetivo de analisar os impactos causados pela pandemia do Coronavírus na educação de crianças com deficiência no município de Cumaru-PE, bem como as estratégias utilizadas para ofertar o conhecimento ao público atendido no Atendimento Educacional Especializado (AEE). Uma educação comprometida com a educação das crianças com deficiência busca diversas estratégias para continuidade e oferta do ensino de forma remota. Por meio de aplicativos como o WatsApp, ou aulas online por meio da ferramenta Zoom, e, para as crianças cuja deficiência inviabiliza o uso da internet são encaminhadas atividades impressas onde com a ajuda dos pais eles respondem e fazem a devolutiva para as correções. Tudo isso foi possível porque os pais estavam comprometidos a ajudar seus filhos em casa, para que durante o período de pandemia não ficasse sem realizar as suas tarefas escolares. A utilização de jogos foi outra proposta lúdica para que todos participem do momento de construção do conhecimento. É um artigo de cunho bibliográfico

\footnotetext{
1 Mestrado em Educação, Pós-graduação em Psicopedagogia, Graduação em Pedagogia.
} 
embasado em Citelli (2000); Silveira (2004); Mantoan (2003) e Freire (2007) dentre outros e quantitativo, pois traz seus resultados consolidados por meio de gráfico. $\mathrm{O}$ mesmo possibilita novos estudos sobre a temática que está em destaque mundial desde dezembro de 2019.

Palavras Chave: Pandemia, estratégias de ensino, lúdico, AEE.

\section{INTRODUÇÃO}

Este artigo tem como objetivo analisar os impactos causados pela pandemia do Coronavírus na educação de crianças com deficiência no município de Cumaru-PE, bem como as estratégias utilizadas para ofertar o conhecimento ao público atendido no Atendimento Educacional Especializado (AEE).

A pandemia chegou ao Brasil e pegou toda a população de surpresa e mostra que 0 professor precisa se reinventar para atender à necessidade dos alunos com deficiência que recebem o Atendimento Educacional Especializado para aprimorar os conhecimentos adquiridos em sala de aula regular.

"A escola não deve temer e nem subestimar o seu diálogo com os meios de comunicação e o uso das novas tecnologias" (CITELLI, 2000, p. 7).

Com todo esse afastamento social causado pela Covid-19 o professor precisa se reinventar para exercer sua profissão de forma dinâmica por meio das tecnologias disponíveis, reelaborando suas aulas para atender o estudante em seu lar.

"O movimento inclusivo acontece por vários setores da sociedade e não apenas pela escola". (SILVEIRA, 2004). O autor deixa claro que a educação é composta por um processo de construção coletiva, onde a família tem função de suma importância na construção do sucesso educacional e social de cada aluno.

Percebe-se que cada ser é único e possui limitações, mas a estimulação precoce dará a esse aluno autonomia e autoconfiança. 
O interesse pelo tema justifica-se pela capacidade que o professor possui em se reinventar e buscar melhorar sua praxe pedagógica, por meio de métodos e estratégias inovadoras que levem o conhecimento até o aluno de forma clara e objetiva através de ferramentas digitais com a capacidade de alcançar a todos ao mesmo tempo, mostrando sua capacidade física, mental e intelectual de reestruturar em meio a um problema de saúde mundial.

\section{METODOLOGIA}

Este artigo é de cunho bibliográfico conforme (LIMA e MIOTO, 2007), pois buscou-se através de coleta de dados em artigos e pesquisa na internet o embasamento para o tema em estudo e quantitativa, por se basear em números concretos e da observação para descrever as informações de forma precisa e objetiva (MARCONI; LAKATOS, 2011).

Tais dados serão apresentados por meio de gráfico, que dará um resultado fechado baseado nos números computados no decorrer da pesquisa.

\section{PANORAMA DO ALCANCE MUNDIAL DA COVID-19}

O Coronavírus é uma infecção respiratória leve, mas que pode se agravar de acordo com cada indivíduo e as doenças pré-existentes. Teve origem na cidade de Wuhan na China no mês de dezembro do ano de 2019.

A cada dia o número de infectados aumentava e na mesma ordem o aumento de óbitos provocado por este vírus. Aqui será demonstrado os números contabilizados entre os meses de março a junho de 2020, com um enfoque no município de CumaruPE.

Já em janeiro de 2020 confirmam-se os primeiros casos no Japão e na Tailândia, pois essas pessoas contaminadas haviam viajado para a cidade de Wuhan. A partir daí a OMS começa a considerar o vírus como ameaça de saúde pública devido à elevação dos casos. 
Neste mesmo mês, surge casos na Costa do Marfim, França e Alemanha e Estados Unidos, ou seja, esse inimigo invisível espalhava-se de forma descontrolada.

No mês de fevereiro já se somavam mais de 44 países com casos confirmados. A partir daí algumas dessas nações optaram pelo fechamento das fronteiras, visando estancar os números de casos. Nesse momento a Itália e o Irã já contabilizavam um aumento excessivo. (OMS, 2020).

No mundo eram mais 80 mil casos e os brasileiros que moravam nesses países decidiram voltar e foram repatriados da China, o epicentro da doença, com a ajuda da força aérea brasileira. Ao chegar ao Brasil, ficavam isolados em quarentena para descartar a contaminação.

No dia 29 de fevereiro, logo após o carnaval surge o primeiro caso de covid-19 no Brasil, um senhor com histórico de viagem recente a Itália. O mesmo tinha 61 anos de idade de acordo com o Ministério da Saúde.

Desde o surgimento do primeiro caso no Brasil a higiene pessoal ganha uma visibilidade nas mídias sociais e na TV. Indica-se lavar as mãos várias vezes ao dia com água e sabão e ao sair levar o álcool em gel para realizar a higienização das mãos.

Em locais com aglomerações fazer uso da máscara, podendo ser descartável ou reutilizável, se a segunda opção for a escolha, ao chegar em casa a mesma deve ser lavada e posta para secar. Já a descartável prestar atenção no tempo de uso e ao descartar colocar em saco plástico amarrado e no lixo do banheiro, nunca no lixo comum. É muito importante também nas filas e locais com muita gente manter um distanciamento de um metro a um metro e meio, conforme as recomendações das autoridades de saúde.

Em março o novo epicentro do Coronavírus passa a ser a Europa, segundo a Organização Mundial de Saúde. 
Neste mesmo mês surge o primeiro caso na Argentina, seria um homem de 64 anos. A partir dos elevados índices de contaminação a OMS declara o estado de pandemia no dia 13 de março de 2020.

A partir daí cada governante obedecendo ao que determina o Ministério da Saúde aplica a quarentena e o isolamento social para controlar o contágio. Neste dia, o primeiro brasileiro contaminado consegue recuperar-se.

Contudo, há uma estabilização na China e em contrapartida a Itália os números continuavam em uma crescente e o número de mortes era maior do que na China.

No dia 17 de março de 2020 é divulgada a primeira morte em território brasileiro atribuída a Covid-19 em uma pessoa do sexo masculino de 62 anos com histórico de Diabetes e Hipertensão, deixando assim, o estado de São Paulo em alerta, e, a partir daí foram se confirmando novas mortes. Todos com histórico de viajem internacional. (MINISTÉRIO DA SAÚDE, 2020).

Diante do alto número o Conselho Federal de Medicina inicia uma busca incansável para combater o Coronavírus. Entra em ação os estudos com a Hidroxicloroquina e Cloroquina para o combate, mas era indicado apenas para pacientes graves.

Com a quarentena, muitas famílias brasileiras perderam a sua renda. O Presidente Jair Bolsonaro no dia 01 de abril sanciona a Lei 13.982/2020 do auxílio emergencial de $R \$ 600,00$ (Seiscentos reais) mensais por três meses e para as mães solteiras esse valor chega a $\mathrm{R} \$ 1.200,00$ (Hum mil e duzentos reais).

Por não existir uma vacina capaz de imunizar a população alguns estados resolveram implantar o lockdown (Fique em Casa).

Em Pernambuco confirmam-se os primeiros casos no dia 12 de março de 2020. Tratase de um casal de 66 e 71 anos respectivamente com histórico de viagem recente para Roma, na Itália. No dia 25 de março registra-se no estado a primeira morte pela Covid-19 em Recife. Um senhor de 85 anos que não havia viajado, porém sofria de diabetes, era hipertenso e cardiopatia isquêmica o que acentua a chance de contrair 
a forma grave da doença e não sobreviver. (SECRETARIA DE SAÚDE DE PERNAMBUCO, 2020).

Nos meses de abril o estado soma 5.358 casos de Covid-19 sendo 3.688 diagnosticados com a forma grave da doença e 1.670 leves, na data da atualização em 27 de abril contabilizava-se 450 mortes e 704 pacientes recuperados. Em maio, no dia 29 o estado de Pernambuco continua com os índices aumentando, o número de infectados chega a 32.225 e 2.669 mortes. Esses são números contabilizados desde o início da pandemia no estado no mês de março. Nesse momento os leitos de UTIs já tinham uma ocupação de 96\%. (SECRETARIA DE SAÚDE DE PE, 2020).

As infecções começam a aumentar também no interior do estado deixando em alerta toda a rede de saúde que já estava próximo aos 100\% de capacidade de atendimento.

Em 29 de junho com a divulgação de mais um boletim da Secretaria Estadual de Saúde (SES-PE) totaliza-se 58.476 casos confirmados e 19.354 casos graves e 39.122 classificados como caso leve, somando-se 4.782 mortes segundo os dados repassados pela SES-PE. (G1 PE, 2020).

De acordo com a (SMS) Secretaria Municipal de Saúde o município de Cumaru-PE confirma o primeiro caso de Covid-19 em 06 maio. Trata-se um/a profissional da saúde que estava na linha de frente e contraiu o vírus. Assim que surgiram os primeiros sintomas o/a mesmo/a ficou em isolamento domiciliar até sua pronta recuperação e a volta ao trabalho. A família fez o teste rápido, mas todos obtiveram o resultado negativo para o Coronavírus.

Com essa confirmação se intensificaram as ações de combate e disseminação do vírus, através de sanitização das ruas e veículos, pontos de higienização das mãos em locais estratégicos no centro da cidade, além de organização de filas para garantir o distanciamento entre as pessoas. Houve também a distribuição de máscaras e vitamina C para fortalecer o sistema imunológico da população.

A Secretaria de Saúde de Cumaru divulga o boletim do dia 07 de maio com 08 casos de Covid-19 confirmados e no dia 08 de maio, são 09 casos comprovados por meio 
de testes, 06 descartados e 04 em investigação. Em 11 de maio eram 10 contaminados por Coronavírus e 05 recuperados e no dia 12 de maio após divulgação do boletim o número de casos confirmados chegam a 12 e os recuperados são 05 pessoas.

A partir daí a Secretaria de Saúde de Cumaru - PE passa a divulgar por meio de boletim epidemiológico os números de contaminados apenas nas segundas, quartas e sextas respectivamente.

Sai mais um boletim epidemiológico no dia 15 de maio com 13 pessoas acometidas pelo vírus e 06 recuperados. Já no boletim divulgado no dia 18 de maio o número de casos confirmados chega a 15 e um total de 08 recuperados. No dia 20 de maio os números de casos confirmados são de 17 pessoas e 12 recuperados. Chega-se ao dia 22 de maio com 20 pacientes confirmados, 13 recuperados e 05 em investigação, conforme a Secretaria de Saúde Municipal.

Em 25 e 26 de maio os números não tiveram alterações somaram 22 casos confirmados de Covid-19, sendo 15 recuperados e 01 em investigação. O boletim epidemiológico publicado em 29 de maio consta de 23 casos confirmados e 18 recuperados e apenas 01 em investigação. No dia 01 de junho tinham 25 casos confirmados 22 pessoas recuperadas e 03 casos em investigação e 02 óbitos em investigação. Em 03 de junho conforme o boletim da Secretaria de Saúde são 25 casos confirmados com o vírus e todos recuperados, mas 01 óbito descartado e 01 permanece em investigação de acordo com dados obtidos pela Secretaria Municipal de Saúde de Cumaru.

Em mais uma divulgação da Secretaria de Saúde do município, chega-se ao dia 05 de junho com um total de 30 casos confirmados para a Covid-19, sendo que desses 28 já estão recuperados e um óbito. No dia 08 é lançado mais um boletim epidemiológico da Secretaria de Saúde Municipal aonde os números vêm em uma crescente, já são 31 casos confirmados, sendo 28 recuperados e apenas um óbito confirmado. Sai mais um boletim com os números do Coronavírus no município no dia 
10 de junho, dessa vez o número de pessoas confirmadas chega a 32, os recuperados somam 28 e um óbito.

Em 12 de junho conforme boletim epidemiológico apresentado pela SMS do município já havia 36 casos confirmados, sendo 29 pacientes recuperados e 01 óbito. No dia 15 de junho o boletim epidemiológico publicado pela Secretaria de Saúde mostrava que haviam 38 casos confirmados e dessas 29 pessoas recuperadas, 01 óbito, mas 06 permaneciam em investigação. No dia19 de junho esse número chegaria a 48 casos confirmados, com 39 pacientes recuperados e um óbito.

Mais um boletim é divulgado pela SMS de Cumaru no dia 22 de junho e apresenta os seguintes números, casos confirmados 52 e recuperados 43 e o número de óbito não foi alterado. Nesse momento 06 casos permanecem em investigação. Dois dias depois eram 54 casos confirmados, 45 recuperados, 01 óbito e 06 pessoas em investigação. No dia 26 de junho os casos confirmados continuam iguais ao último boletim, mas os recuperados sobem para 47e 10 munícipes continuam em investigação. O número de óbito permanece em 01 . E no dia 29 de junho o número chega a 59 infectados, 54 recuperados e 09 pacientes em investigação. E em 30 de junho já eram mais de 187 países com casos confirmados com o vírus SARS-CoV-2.

\section{O AEE E SUA FUNÇÃO NA APRENDIZAGEM DA CRIANÇA EM TEMPOS DE PANDEMIA}

O Atendimento Educacional Especializado tem a função de identificar os problemas de aprendizagem para elaborar e organizar através de recursos pedagógicos acessíveis a eliminação de barreiras para a participação efetiva de alunos com deficiência, respeitando suas especificidades.

De acordo com Mantoan:

A escola prepara o futuro e, de certo que, se as crianças aprenderem a valorizar e a conviver com as diferenças nas salas de aula, serão adultos bem diferentes de nós, que temos de nos empenhar tanto para atender e viver a experiência da inclusão (MANTOAN, 2003, p. 91). 
Esse atendimento objetiva complementar o aprendizado do aluno, possibilitando o seu crescimento e independência, nunca substituir a sala de aula regular, por isso o seu funcionamento é no contraturno em que o aluno estuda.

O público alvo para o atendimento no AEE são crianças com deficiência física, intelectual, visual, auditiva, com transtorno global do desenvolvimento e com altas habilidades/superdotação, com foco na promoção da autonomia e liderança.

Com a pandemia da Covid-19 no mundo, e, consequentemente no Brasil, toda a rede escolar, seja ela, pública ou privada ficou comprometida. As aulas da rede municipal de ensino em Cumaru teve início no dia 17 de fevereiro, mas um mês depois os gestores suspenderam as atividades por conta do crescimento dos números de contágio. A princípio seriam 15 dias de afastamento, mas como a curva da doença estava em ascendência os estudantes permaneceram em casa e passaram a ter aulas remotas e o profissional de ensino precisou se reinventar. Como afirma Piaget (1994, p. 96) "o principal objetivo da educação é criar pessoas capazes de fazer coisas novas e não simplesmente repetir o que as outras gerações fizeram". E a LDB 9394/96 em seu $\S 4^{\circ}$ acrescenta que "O ensino fundamental será presencial, sendo o ensino a distância utilizado como complementação da aprendizagem ou em situações emergenciais".

No AEE estas aulas funcionam da seguinte forma. A coordenadora juntamente com os profissionais realizava reuniões por meio de aplicativos como o Zoom ou Google Meet para traçar as metodologias adotadas e poder levar as atividades até os alunos.

Para os alunos que possui internet ministra-se vídeo aulas, criou-se também grupo de WhatsApp, e para os que não têm acesso a celular com internet as atividades são impressas e entregue em suas casas e posteriormente os professores com dia e horário marcados recolhiam essas atividades. $E$ desde então este está sendo o dia a dia do professor do Atendimento Educacional Especializado. Portanto é necessário de acordo com Masetto:

Uma mudança de atitude em relação à participação e compromisso do aluno e do professor, uma vez que olhar o professor como parceiro 
idôneo de aprendizagem será mais fácil, porque está mais próximo do tradicional. Enxergar seus colegas como colaboradores para seu crescimento, isto já significa uma mudança importante e fundamental de mentalidade no processo de aprendizagem (MASETTO, 2000, P. 141).

Como se trata de alunos com deficiência a cada entrega contempla-se os jogos, pois assim todos em casa participam do momento de aprendizagem. Como nos diz Freire (2007, p. 25) "ensinar não é transmitir conhecimento, mas criar possibilidades para sua produção ou a sua construção".

A educação é um processo dinâmico, onde a interação com o outro potencializa o conhecimento e o lúdico é uma ferramenta que possibilita esse desenvolvimento também em família. $O$ brincar surgiu desde os primórdios dos tempos e tem uma ligação com a afetividade e a cultura de cada povo (CABREIRA; SALVI, 2005). No mês de junho a equipe do AEE traz um projeto com o tema Dançando em Casa. Onde toda a família reúne-se para vestir-se de caipira, mandar fotos ou vídeos onde a coordenadora da educação inclusiva arquivou todos os recebidos e compilou para uma produção única.

Mesmo com todo esse empenho sabe-se que não se atinge a todos os alunos. As atividades demoram a chegar aos que residem distante do centro, outros não conseguem realizar as atividades propostas, mas tudo está sendo feito para atingir o maior público possível.

\section{RESULTADOS E DISCUSSÕES}

Os resultados serão compilados por meio de gráfico que contabilizará os números da Covid-19 no município de Cumaru - PE entre os meses de março a junho de 2020, período em que a pesquisa foi realizada. 
Gráfico 1: Mostra dos números da Covid-19 entre os meses de março a junho.

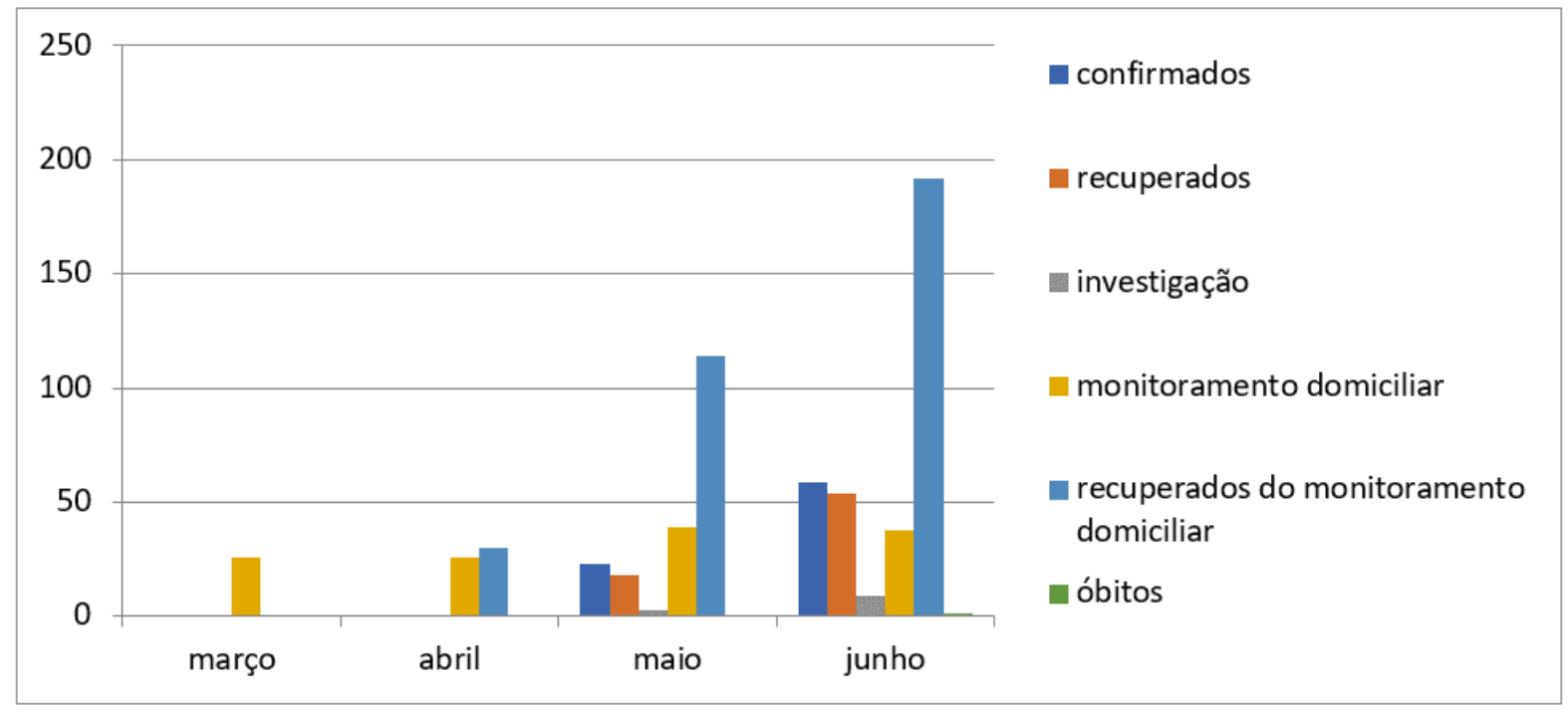

Conforme a exposição do gráfico e por meio da observação de sua legenda fica claro que houve um aumento no número de casos recuperados no monitoramento domiciliar, mas em contrapartida o número de pacientes confirmados com o coronavírus continua em ascensão e os óbitos já são três no município de Cumarru entre os meses pesquisados. De acordo com (RADIS, 2020), a Organização Mundial de Saúde, alerta que as pessoas permaneçam em seus lares para que haja uma diminuição nos casos de Covid-19 e consequentemente uma estabilização nos números no âmbito internacional.

Como o contágio ocorre por meio do contato, manter o distanciamento social e a higienização correta conforme preconiza a Organização Mundial de Saúde é importante para o combate ao Coronavírus e a diminuição de outras patologias existentes no ambiente.

\section{CONSIDERAÇÕES FINAIS}

É preciso reconhecer que o AEE é de suma importância na vida escolar da criança com deficiência e atua como um espaço de complemento de aprendizagem. Luta-se diariamente para que esses estudantes se desenvolvam diante de suas 
particularidades e torne-se uma pessoa autônoma mesmo com todas as suas limitações.

O Atendimento Educacional Especializado tem o compromisso de propiciar um futuro digno às crianças, portanto sabe da importância da ludicidade, do trabalho em grupo e da interação com os pares para desenvolver as potencialidades de cada indivíduo. O profissional que atua nesse espaço busca criar possibilidades através de recursos para facilitar e contribuir de forma ativa na vida desse aluno.

Formar indivíduos autônomos, criativos e críticos que busque seu espaço na sociedade é o compromisso de uma educação inclusiva de qualidade para todos.

O modelo de educação no Brasil teve que fazer adaptações os professores tiveram que se reinventar, pois essa pandemia nos mostrou que o distanciamento era necessário para a saúde coletiva.

Enfim, considero um ano escolar atípico, mas com aprendizagem que nos tornará seres diferentes. A união de forças de todos que fazem parte do processo ensino e aprendizagem; além da família, o fortalecimento do vínculo tornou possível e promoveu uma construção sólida durante o período de isolamento social.

A pandemia da Covid-19 veio e modificou todos os planos para uma educação presencial, como o toque, o carinho e o afeto, mas deixa o ensinamento de que a valorização da família é essencial. Esse tema é estimulante, instiga a todos, pois o mesmo não se esgota aqui, portanto é provocativo bem como estimulante, merecendo atenção de pessoas que se interessem em acrescentar novos contextos e possíveis soluções para a vida após a reabertura das escolas.

Fica aqui algumas indagações, como será esse novo normal pós pandemia do Coronavírus? Como voltarão os alunos e professores quando retornar as aulas presenciais? Talvez se tenha uma resposta no futuro, mas hoje é tudo muito incerto, no desejo de novas pesquisas fica claro que é uma temática inesgotável e requer novos estudos. 


\section{REFERÊNCIAS}

BRASIL. Ministério da Saúde. Secretaria de Políticas de Saúde. Brasília, 2020.

BRASIL. Lei de Diretrizes e Bases no 9394/96. Acesso no dia 29 de jun. de 2020 as $10: 23$ em: http://www.educacao.sp.gov.br/lise/legislacaocenp/LEl\%20N\%C2\%BA\%209\%20394 \%20DE\%201996\%20-\%20LDB\%20-\%20LEIS\%20ALTERADORAS.pdf, p.10.

CABREIRA, W. B.; SALVI, R. A Ludicidade no Ensino Médio: Aspirações de Pesquisa construtivista. Associação Brasileira de Pesquisa em educação.

CITELLI. A. linguagem e Persuasão. 15ª edição. São Paulo. Ática, 2001.

EMERGÊNCIA INTERNACIONAL. Revista Radis, oㅡ 210, mqrço, 2020.

FREIRE, P. Educação e Mudança. 30 ed. Rio de Janeiro: Paz e Terra, 2007.

GIL, A. C. Metodologia do ensino superior. 4. ed. São Paulo: Atlas, 2011.

GOVERNO DO ESTADO DE PERNAMBUCO/SECRETARIA DE SAÚDE DE PERNAMBUCO, 2020.

G1. Disponível em: https://g1.globo.com/pe/pernambuco/noticia/2020/06/29/pechega-a-58476-infectados-e-4782-mortes-por-covid-19-apos-mais-369-casos-e-31obitos.ghtml.

MARCONI, M. A; LAKATOS, E. M. Metodologia científica. 6. ed. São Paulo: Atlas, 2011.

LIMA, Telma Cristiane Sasso de and MIOTO, Regina Célia Tamaso. Procedimentos metodológicos na construção do conhecimento científico: a pesquisa bibliográfica. Rev. katálysis [online]. 2007, vol.10, n.spe, pp.37-45. ISSN 19820259. https://doi.org/10.1590/S1414-49802007000300004. Acesso em 27 de jun. de 2020 as $10: 44$. 
MANTOAN, Maria Teresa Eglér. Inclusão escolar: O que é? Por quê? Como fazer? São Paulo: Moderna, 2003.

MASETTO, M. T. Mediação pedagógica e o uso da tecnologia. In MORAM, J. M.; MASETTO, M. T.; BEHRENS, M. A. Novas tecnologias e mediação pedagógica. Campinas: Papirus, 2000.

https://www.paho.org/pt/covid19. Folha informativa COVID-19 - Escritório da OPAS e da OMS no Brasil, 2020.

PIAGET, J. Citado em "Correntes pedagógicas: aproximações com a teologia" Página 96, de Danilo Romeu Streck - Vozes, 1994, ISBN 8532612164, 9788532612168 - 136 páginas. Acesso em 25 de jun. de 2020 as 09:36.

SECRETARIA MUNICIPAL DE SAÚDE DE CUMARU, 2020.

Enviado: Julho, 2020.

Aprovado: Agosto, 2020. 